\title{
Engagement with a Multi-Component, Preventative Program to Reduce Child Maltreatment: Program Satisfaction and Acceptability
}

\author{
Yvonne Leckey $^{1}$ (1) $\cdot$ Ann Stokes ${ }^{1} \cdot$ Gráinne Hickey $^{1} \cdot$ Sinéad McGilloway $^{1}$
}

Accepted: 11 January 2021 / Published online: 20 February 2021

(c) The Author(s) 2021

\begin{abstract}
The development and implementation of interventions to prevent child maltreatment $(\mathrm{CM})$ is particularly challenging in view of the numerous stressors experienced by families within the child welfare system (CWS). Difficulties engaging families, particularly those who are most vulnerable, can lead to lower program dose and poorer outcomes. This qualitative study, conducted as part of a larger process evaluation, explored participant perspectives of a newly developed, multi-component, community-based intervention designed to reduce the risk of CM in families with young children. The study involved one-toone interviews with a sub-sample of mothers $(\mathrm{n}=12)$ recruited through statutory and community-based social work services. Several brief program satisfaction questionnaires were also completed by parents. Mothers reported a stronger parent-child bond and greater use of positive parenting strategies (e.g. improved communication and discipline strategies) following the intervention. Facilitator and group support emerged as strong themes throughout the interviews and were important factors in facilitating engagement and reducing drop-out. High levels of program satisfaction were also reported. The study findings demonstrate how a multi-component program, which combines an evidence-based treatment (EBT) with community-based supports, may offer a promising approach for social work practitioners in reducing CM and in better meeting the more complex needs of families within the CWS. However, a more thorough understanding of the factors which promote program engagement and retention, is crucial to maximizing the benefits of interventions designed to support more vulnerable families.
\end{abstract}

Keywords Child maltreatment $\cdot$ Child welfare services $\cdot$ Evidence-based treatment $\cdot$ Parent perspectives $\cdot$ Program engagement and retention

\section{Introduction}

Child Maltreatment (CM) affects over 55 million children within the European region and is widely considered to be a global public health issue (Gilbert et al. 2009; Sethi et al. 2018). Exposure to CM is strongly linked to adverse health and wellbeing outcomes, including emotional and behavioral problems (Éthier et al. 2004), cognitive impairment, poor educational achievement (Nikulina, Widom and Czaja 2011), mental health disorders (Nanni et al. 2012), substance misuse (Norman et al. 2012) and poorer education and employment opportunities (Currie and Widom 2010). Without intervention, these outcomes may extend

Yvonne Leckey

Yvonne.Leckey@mu.ie

1 Department of Psychology, Centre for Mental Health and Community Research, Maynooth University, Maynooth, Co Kildare, Ireland into adult life, thereby contributing to important intergenerational effects (Lakhdir et al. 2019). Furthermore, there are substantial economic and societal costs associated with $\mathrm{CM}$ which indicate an urgent need for effective, preventative, programs in early childhood (Fang et al. 2012). The World Health Organization recommends that programs to prevent CM should be evidence-based, adopt a multi-disciplinary approach, be culturally appropriate and provide suitable supports, such as transport and childcare, to facilitate attendance (Hardcastle et al. 2015).

\section{Review of the Literature}

Effective prevention strategies for CM typically target parenting skills to promote optimal child development and encourage stable and nurturing relationships (Fortson et al. 2016). There is a strong evidence base for the effectiveness of parent training (PT) programs and, in particular, the extent to which they reduce harsh and dysfunctional 
parenting and promote positive parent-child interactions (Furlong et al. 2010; Knerr, Gardner and Cluver 2013). More recently, meta-analyses of PT programs have shown that parent training offers an effective approach in preventing or reducing child maltreatment (Chen and Chan 2016; Euser et al. 2015). One of the most widely used and rigorously evaluated PT programs is the Incredible Years Parenting Program (IYPP) (e.g. Gardner and Leijten 2017; Menting de Castro and Matthys 2013; Pidano and Allen 2015) which was developed in the US and has been identified as an effective program by the California Evidence Based Clearinghouse for Child Welfare (CEBC) and Substance Abuse and Mental Health Services Administration (SAMHSA). Particular aspects of the program are considered to be effective in reducing $\mathrm{CM}$ including, for example, strengthening the parent-child bond and developing effective parenting techniques to bring about behavioral change, while the groupbased program format and collaborative discussion helps to reduce stigma and social isolation, leading to increased participant engagement and motivation (Webster-Stratton and Reid 2010). Maltreated children often experience harsh and inconsistent parenting which places them at higher risk for developing insecure attachment. Thus, developing sensitive and nurturing parenting - in line with attachment theory (Bowlby 1982) - is fundamental to appropriately responding to the emotional needs of the child (Harden et al. 2016). More recently, the program has been successfully adapted for use with children in the welfare system (Hurlburt et al. 2013; Letart et al. 2010; Marcynyszyn et al. 2011) and participation has been found to substantially increase the probability (by over a third) of a child's case being closed (Sicotte et al. 2018).

Home visiting (HV) programs are also effective in preventing $\mathrm{CM}$ and are particularly beneficial for vulnerable, isolated, or high-need families (Avellar and Supplee 2013). $\mathrm{HV}$ programs encourage engagement by providing individualized services to families in their own homes (DonelanMcCall, Eckenrode and Olds 2009). Consequently, home visitors are often best placed to identify and address the risk for $\mathrm{CM}$, by fostering positive parenting practices and connecting families to appropriate resources and supports (Schreier et al. 2020). Programs such as the Nurse Family Partnership (NFP), Healthy Families America (HFA) and Early Head Start (EHS) have demonstrated positive outcomes in terms of improved and less chaotic home environments, as well as fewer child protective services (CPS) reports (Green et al. 2014; LeCroy and Lopez 2018; Mejdoubi et al. 2015). Overall, however, the impact of HV programs is relatively modest when compared to PT programs, due primarily to the wide variation in their approach and implementation (LeCroy and Lopez 2018). Indeed, a recent meta-analysis showed that implementation-related factors, such as reflective supervision and high levels of fidelity monitoring, are critical to producing positive outcomes (Casillas et al. 2016).

Despite increased awareness of the importance of evidence-based treatments (EBTs) within child welfare services (CWS), the uptake and implementation of such interventions are relatively limited (Landers et al. 2018; Levey et al. 2017). A recent US study highlighted the poor adoption of EBTs within organizations involved in CWS, with many organizations citing a perceived lack of fit with service users, or a preference to implement existing non-evidence-based practices (Karatekin 2014). One of the key challenges to the implementation of EBTs for families at risk of CM is uptake and engagement, particularly given the levels of service mistrust amongst parents, the stigma associated with CWS and the multiple stressors experienced by families (Gilbert et al. 2009). High rates of attrition also pose a significant problem among families who engage with CWS (Kemp et al. 2014), resulting in increased costs and lower program reach (Baker, Arnold and Meagher 2011).

Importantly, program engagement is vital, not only to improve parental and child outcomes, but also to mitigate against the placement of children in foster care (Price et al. 2008). Evidence shows that numerous individual, family and community factors have been found to hinder treatment and engagement (Staudt 2007). For example, inadequate housing, poverty, unemployment, lack of childcare and transportation and competing responsibilities and demands, have been previously identified as barriers to parent engagement (Garcia et al. 2018). Indeed, addressing practical barriers (such as transportation, conflicting schedules or childcare) is essential to improving retention for vulnerable families (Ingoldsby 2010; Rostad et al. 2018). Moreover, individual factors such as client motivation, as well as program relevance and acceptability, are also receiving greater attention in terms of improving outcomes and population reach (Landers et al. 2018; Sanders and Kirby 2012). Understanding how parents perceive the child welfare system, their satisfaction with a service and the way that service is delivered, can improve parenting outcomes (Gladstone et al. 2014). Therefore, a greater understanding of implementation issues, such as how parenting support is delivered, in addition to what is delivered, may be a critical factor in achieving positive outcomes (Moran Ghate and van der Merwe 2004). As funding organizations and policymakers increasingly require the integration of EBTs into clinical practice, agencies and CSWs are faced with the challenge as to how best this might be achieved (Bledsoe-Mansori et al. 2013). EBTs can often be viewed as a poor fit to adequately address the contextual or cultural concerns of certain clients, particularly families who present with more complex issues (Wike et al. 2014). Nevertheless, an opportunity exists for clinical social workers to integrate specific components into existing EBTs in order to optimize outcomes among higher risk populations. 


\section{Intervention}

Given the multifactorial and complex nature of $\mathrm{CM}$, more intensive interventions which target individual as well as broader contextual factors may be necessary to prevent child abuse and neglect (Asawa, Hansen and Flood 2008). The Children At Risk Model (ChARM) service model, which is the focus of this paper, aims to address the multiple and complex needs of families where children (aged 3-11 years) are at risk of physical and emotional child abuse as well as neglect. The model comprises four core components delivered consecutively including: (1) a Positive Life Skills Program (PLSP) (4 weeks); (2) the Incredible Years Parenting Program (IYPP) (14 weeks); (3) home visits (HVs) and (4) referrals to additional community supports/services where necessary (see Fig. 1).

The PLSP is a new, brief, manualized parent-engagement program (comprising two to four weekly two-hour sessions) specially designed to encourage vulnerable, hard-to-reach parents to engage with services. The program was developed by Social Care Leaders based in South Dublin in Ireland who identified a need for their clients to build their self-esteem, and group-based engagement skills, in order to enable them to engage appropriately with, and participate in, the IYPP. There are, of course, many complex factors which may act as barriers to such engagement; this program aims to address some of them, including improving parental confidence and self-esteem, providing information on child development and stress management techniques, and promoting a better parent-child relationship and decision-making around child needs. Importantly, it focuses on parents' individual needs (such as parental capacity to meet child's needs, parental coping skills and resilience) whilst addressing the psychological barriers of fear and stigma, which may

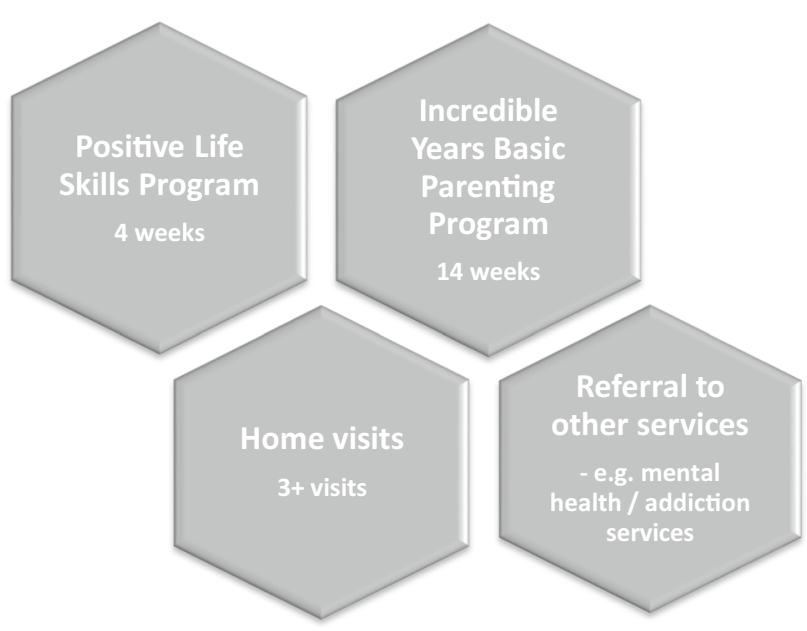

Fig. 1 Overview of the ChARM program limit engagement with services. An action plan is created as part of the program to improve coping skills and resilience and understand any resistance or conflict to engaging with services; facilitators work closely and collaboratively with parents to overcome these difficulties. The PLSP also aims to build working relationships with the social work team and to better connect parents with necessary services and supports.

The IYPP (Webster-Stratton et al. 1998) promotes positive parent-child relationship, positive parenting and child behavior by reducing harsh discipline and increasing positive discipline strategies, as well as improving parental self-control and wellbeing. The program was selected for use here due to its strong international evidence base and the availability of professional personnel to deliver the IYPP in the areas where the research was being conducted. The program is also widely used, and has been evaluated, in Ireland (e.g. McGilloway et al. 2012). It comprises 14 weekly, two-hour parent-group training sessions and has demonstrated effectiveness in improving child behavior and parenting skills, particularly within high risk populations (Menting et al. 2013). There is growing evidence to support the use of IYPP for families within the child welfare system with a number of studies demonstrating stronger parent-child relationships, improved discipline strategies and enhanced parental mental health (Letarte, Normandeau and Allard 2010; Marcynyszyn et al. 2011; Webster-Stratton and Reid 2010). While the IYPP has a home visiting component, this is typically delivered on a supplementary basis such as on occasions when parents miss sessions or require additional practical help in the home. In this study, structured home visits were provided in parallel to the delivery of the IYPP and were designed to reinforce the uptake of positive parenting principles taught in the IYPP (Lees and Fergusson 2015). Visits lasted approximately 60-90 min and were delivered by facilitators using the IY principles and techniques, to support parents in implementing parenting practices in the home, and in tailoring strategies to meet their child's needs. Minimizing drop-out was also a key feature of the HVs; thus, a positive facilitator-parent relationship was encouraged to build trust, allay parents' fears and respond more appropriately to parents' needs (Schreiber et al. 2013).

Facilitators also addressed barriers to attendance by reimbursing any costs associated with transport (bus or taxi services) and childminding as well as encouraging participants to link in with other community services where necessary. Additional supports accessed by participants were recorded both quantitatively and qualitatively over a 12-month period. The ChARM program was delivered in community-based settings (community centers) and the combination of all four program components was designed to address common barriers to attendance (namely, distrust of CWS and supports, stigma associated with parenting programs, lack 
of confidence/self-esteem) and increase rates of participation among more vulnerable families who are less likely to engage with services.

The current ChARM program was undertaken as part of a larger (mixed methods) evaluation involving an exploratory $\mathrm{RCT}$, a process evaluation and a cost-effectiveness analysis, the findings of which are currently being prepared for publication (McGilloway et al. 2019). The study was conducted in line with the Medical Research Council framework for developing and evaluating complex interventions (MRC 2000), with a view to informing the ongoing development and future implementation of the program. The RCT involved 41 families (21 intervention and 20 control) who were identified by statutory and community-based child welfare and social work services as being at risk of CM, and assessed program impact on child abuse and neglect to determine any changes in parental practices and child behavioral outcomes. The embedded process evaluation was conducted to explore program implementation, including enablers and barriers to implementation, as well as program acceptability, engagement and mechanisms of impact.

The principal aim of the study reported here-which was conducted as one discrete element of the process evaluation-was to explore parent participants' experience of, and engagement with the ChARM program. The study objectives were to: (i) examine program uptake and factors that influenced engagement and satisfaction; (ii) explore participants' perceptions of the benefits of involvement and the extent to which the program had met their needs; and (iii) identify enablers and barriers to engagement.

\section{Program Delivery, Implementation and Fidelity}

\section{Program Delivery}

As the ChARM program involved delivery strategies that were new to practitioners, some implementation difficulties were encountered. Two programs (Cycle 1 and 2) were delivered in an urban site with the final program delivered in a rural location (Cycle 3). After the first cycle of delivery (Cycle 1), facilitators felt that some of the PLSP content overlapped with aspects of the IYPP and, as a result, for the second cycle of delivery, the PLSP content was condensed and delivered over a two-week period. Similarly, the IYPP was reduced from 14 to 12 weeks in this cycle to promote engagement with a highly vulnerable group. However, for Cycles 1 and 3, program content was delivered as intended, over an 18-week period. The rural site (Cycle 3 ) also experienced challenges in terms of recruiting participants due to their geographical spread and the distances involved in travelling to take part in the program. Consequently, two participants allocated to the intervention were unable to attend.
Four personnel were involved in delivering all four program components. All facilitators were trained and experienced in the delivery of the IYPP and had previous experience of delivering the program with high risk families. Facilitators were also trained to deliver the PLSP prior to program commencement and had direct experience of delivering individual home supports to vulnerable families. Within the urban site, two facilitators had considerable experience in working within the child welfare and protection system in Ireland. (i.e. a formal recognized qualification such as a National Social Work Qualification (NSWQ)), plus at least 5 years working directly within the child protection, early intervention and family support services in a senior role. The remaining two community-based facilitators had extensive experience in delivering the IYPP, one of whom is a certified Incredible Years Group Leader. Facilitators received regular peer supervision in a group-setting with a locally trained Incredible Years healthcare psychologist. In addition, two (who were trained Social Workers) also received supervision from their Line Manager which included additional topics such as supporting parents and improving engagement. Facilitators also completed leader session checklists and received peer support coaching (depending on level of experience) for the duration of the program to ensure high fidelity training and implementation. At the time of delivery, two facilitators were fully accredited while the others were in the process of accreditation.

Given the high levels of need presented by families, most of the parents in the program had allocated Social Workers, but no facilitators in this study acted as Social Workers for parent participants. Throughout the program, facilitators worked closely with participants not only to improve parenting knowledge and skills but also to explore barriers to attendance. Through informal conversations with facilitators during the program, parents could request extra help or support whereby facilitators would liaise with relevant Social Workers and Family Support Workers on their behalf in accessing services within the community.

\section{Method}

\section{Participants}

Qualitative data collection and analysis were guided by the Consolidated Criteria for Reporting Qualitative Studies (COREQ) guidelines (Tong et al. 2007). This, mainly qualitative, study included participants from the larger RCT which involved the allocation of 21 participants to the ChARM intervention. The program was delivered over three cycles (Cycles 1, 2 and 3) and in two sites (one urban and one rural). The eligibility criteria was as follows: (a) participants must be the primary caregiver of a child aged between 
3-11 years; (b) the child was identified as being at risk of abuse/neglect by a child welfare professional according to the Hardiker model (Hardiker et al. 1991) (see below) or where it was known by child welfare professionals that a level of child maltreatment had occurred, but the child was still living within the home (i.e. not placed in state care); and (c) participants must be stable in terms of mental illness and substance misuse.

The child's level of risk was assessed according to the Hardiker model (levels 1-4) which is widely used in child welfare and protection services in both the UK and the Republic of Ireland as a planning framework for the categorization and provision of family supports (Hardiker et al. 1991). Within this model, Level 1 refers to the provision of universal preventative supports, and Level 4 represents intensive, long-term supports. The risk levels of study participants ranged from Level 2 to Level 4. Most referrals to the program arose as a result of perceived risk of CM, conduct problems in the home and/or the lack of parenting skills to appropriately manage the child's behavior and address their needs. Scores on the Strengths and Difficulties Questionnaire (SDQ), completed by parents as part of the RCT, revealed a total score of 18.5 indicating 'high' behavioral problems at baseline.

A total of 21 participants took part in the larger evaluation, all of whom were mothers. Six mothers were unable to participate in the program citing personal reasons such as illness, moving house or lack of support in the home. A subsample of 15 mothers, were then selected randomly across the three cycles of delivery and contacted by telephone to ascertain their interest in the qualitative study. Twelve expressed an interest but, the remaining three did not wish to take part. Nine out of the 12 participants completed the program and three dropped out within the early stages of the program. Most of the index children in these families were under 10 years old $(\mathrm{M}=7.8$ years); four were aged 10-11 years. We found no significant differences between the 12 study participants study and the remaining parents allocated to the intervention group in terms of level of risk or urban/rural divide.

\section{Procedure}

All participants provided their written informed consent to take part, and for interviews to be audio recorded. Prior to interviews, parents were informed of the researcher's mandatory duty to report suspected incidents of abuse in line with national protocol and legal guidelines (Dept. of Children and Youth Affairs, Children First: National Guidelines for the Protection and Welfare of Children 2017). Parent interviews were conducted one to four months post-intervention in parents' homes and were conducted by one (female) researcher who was previously involved in data collection for the larger evaluation. It was felt that participants would be more willing to be interviewed by a member of the research team rather than someone who was not known to them. Interviews were audio-recorded with consent, password protected and stored electronically on a secure server. All researchers had a background in psychology or other social science discipline and were highly experienced in undertaking qualitative research with vulnerable families. Parents were given a shopping voucher as a small token of our thanks for participating in the research study. While the study is based primarily on qualitative data, the findings are supplemented with data from quantitative assessments of program satisfaction and attendance, usefulness of program techniques and facilitator skills.

\section{Measures}

\section{Qualitative Data}

Participant experiences and views were explored through one-to-one interviews and parental feedback forms. A semistructured interview schedule (see Appendix) was devised for participants and included open-ended questions about their motivation to attend the program, experiences of the program components, particular techniques/aspects they found useful as well as any perceived changes in the relationship with their child. Other main themes included personal benefits as a result of participation, group and facilitator support and program challenges. Main themes were used as a starting point and the open questions enabled participants to elaborate on their perceptions, and experiences, of the program. They were also asked what services and supports they were accessing and whether the program addressed their needs. Interviews lasted approximately $35 \mathrm{~min}$.

\section{Quantitative Data}

Parental Feedback Forms (PFFs) were completed by mothers for the PLSP and the home visits (HVs). Information on the IYPP was gathered separately (see below). These data were included to complement the qualitative findings by focusing on key program components, and to provide more information on program techniques and practices. However, due to an administrative error in one cycle of delivery (Cycle 3), no forms were completed so unfortunately, this information was not available from the service provider. These forms were developed specifically for purposes of the study by the research team to assess the benefits of both the PLPS and home visits. Each questionnaire comprises a mix of closed and open-ended questions designed to elicit information on which aspects of the program participants they preferred/ 
disliked, whether the program had helped them personally, or in their relationship with their children, as well as facilitator support for them and their family. The IYPP was assessed by mothers using the standardized Parent Program Satisfaction Questionnaire on which participants were asked to rate (using a Likert scale (1-7) the overall program and the difficulty or usefulness of program methods, learning techniques, and abilities of group leaders.

\section{Data Analysis}

\section{Qualitative Data}

The aim of the analysis was to explore participant experiences of the program and identify factors influencing participant satisfaction and engagement with the ChARM program. Interviews with mothers were transcribed verbatim and subjected to a standard thematic analysis (Braun and Clarke 2006) using MAXQDA 12 (VERBI software), a widely used Computer Assisted Qualitative Data Analysis software package which was used here to classify and organize the interview data. Initially, all transcripts were read several times, line by line, by one researcher (YL) who was not involved in the collection of qualitative data. During this open coding phase, initial codes were generated from the dataset which identified repeated patterns and issues related to the research questions. Similar codes were then organized into themes which corresponded specifically to facilitators or barriers to program participation and satisfaction. More detailed coding was undertaken to generate a detailed set of sub-themes for each dominant theme, for example, enablers to engagement such as peer support and improved mental wellbeing. Finally, all themes were checked in relation to the entire dataset to ensure they were distinctive enough from each other and that no other themes were evident. Themes were also further analyzed and compared across study sites and participants to determine differences, if any, in terms of facilitator competencies and urban/rural location. A second researcher (AS) involved in data collection, separately analyzed the data, and coding was compared at various stages to clarify the identification and definition of themes and to resolve any discrepancies. All codes and themes were crosschecked for consistency across all interviews, and themes were discussed with the wider research team for further validation.

\section{Quantitative Data}

Post-program analysis was undertaken on parent-completed questionnaires, including the Parental Feedback Forms (PFF) for both the PLSP and HVs, plus the IYPP Parent
Program Satisfaction Questionnaire. These results are presented alongside the qualitative data.

\section{Results}

\section{Profile of Participants}

Mothers were on average 35 years old and equally divided by marital status (i.e. six were married/co-habiting and six were single) (Table 1). Four were of non-Irish ethnicity and almost half were early school leavers $(n=5)$. Eight families were living in council/social housing and all but two families had an annual household income of under $€ 24,000$. Data from the Survey of Income and Living Conditions (SILC) (Central Statistics Office 2017) states an equivalized household income of below $€ 24,000$ per annum as the threshold for risk of poverty (Central Statistics Office 2018). Nine mothers were unemployed $(n=9)$, and the remainder were working on a part-time basis only. The median number of children in the home was three, and four families had children (other than the index child) living outside the home. All families had children at risk of conduct disorder based on two or more of the following variables: lone or teen parent, ongoing or previous history of mental health problems, family trouble with police, and low family income (under $€ 24,000$ per annum). Five parents were experiencing mental health issues (mainly depression) and five had little or no family support. At the time of the interview, mothers were accessing various statutory and community services, with most availing of Family Support Services, followed by social work involvement and community organizations, such as Irish Society for the Prevention of Cruelty to Children (ISPCC), Daughters of Charity (Child and Family Service), St Vincent De Paul, Child and Adolescent Mental Health Services (CAMHS) and statutory psychological services.

\section{Quantitative Data}

\section{Program Attendance}

Program attendance is shown in Table 2. Given the program adaptations in Cycle 2, participants who completed two weeks of the PLSP are considered here as having completed 4 sessions while the IYPP was reduced to 12 weeks. Overall program attendance for the PLSP indicates that 9 mothers attended for 3-4 weeks. Attendance for the IYPP shows that for Cycles 1 and 3, mean attendance was 9/14 sessions and for Cycle 2 was $7 / 12$ sessions. Three participants had poor attendance (less than 4 IYPP sessions) and subsequently dropped out of the program, with two parents citing physical/mental health illness, and another reporting a busy home life. When these parents are excluded, the mean 
Table 1 Demographic participant characteristics $(n=12)$

\begin{tabular}{|c|c|}
\hline & $\mathrm{N}=12$ \\
\hline \multicolumn{2}{|l|}{ Age } \\
\hline $23-29$ & 3 \\
\hline $30-35$ & 3 \\
\hline $36-40$ & 3 \\
\hline $41+$ & 3 \\
\hline \multicolumn{2}{|l|}{ Marital status } \\
\hline Married/Co-habiting & 6 \\
\hline Single & 6 \\
\hline \multicolumn{2}{|l|}{ Education } \\
\hline Degree/Professional qualification & 1 \\
\hline Post-school (non-Third level) & 4 \\
\hline Completed school & 2 \\
\hline Early school leaver & 5 \\
\hline \multicolumn{2}{|l|}{ Work status } \\
\hline Part-time & 3 \\
\hline Unemployed & 9 \\
\hline \multicolumn{2}{|l|}{ Annual household income } \\
\hline Under $€ 24,000$ & 10 \\
\hline$€ 24,000$ and higher & 2 \\
\hline \multicolumn{2}{|l|}{ Ethnicity } \\
\hline Irish ethnicity & 8 \\
\hline Non-Irish ethnicity & 4 \\
\hline Risk of Conduct Disorder* & 12 \\
\hline \multicolumn{2}{|l|}{$\geq 2 / 6$} \\
\hline \multicolumn{2}{|l|}{ Home ownership } \\
\hline Privately renting & 2 \\
\hline Council/social housing & 8 \\
\hline Sharing/co-op & 2 \\
\hline \multicolumn{2}{|l|}{ Number of children in home } \\
\hline $1-2$ children & 4 \\
\hline $3-4$ children & 5 \\
\hline $5-6$ children & 3 \\
\hline Median number of children in home & 3 \\
\hline Children living outside home & 4 \\
\hline $\begin{array}{l}\text { Currently suffering depression or other mental health } \\
\text { problem }\end{array}$ & 5 \\
\hline \multicolumn{2}{|l|}{ Support from family or friends } \\
\hline A lot/a fair amount & 7 \\
\hline A little/none & 5 \\
\hline Physical/emotional abuse in previous relationship & 3 \\
\hline Physical/emotional abuse in current relationship & 1 \\
\hline
\end{tabular}

*Risk of Conduct Disorder was based on a score of two or more of the following variables: lone parent, teen parent, ongoing or history of mental health problems, trouble with police, partner/father trouble with police, and low family income (under $€ 24,000$ per annum)

attendance for the IYPP rises to 11/14 sessions (Cycles 1 and 3) and $9 / 12$ sessions (Cycle 2), thereby suggesting that these participants were sufficiently motivated to engage throughout the program. The number of HVs for each family
Table 2 ChARM Program attendance $(n=12)$

\begin{tabular}{ll}
\hline & $\mathrm{N}=12$ \\
\hline Positive Life Skills Program (PLSP) & \\
Completed 1 week & 1 \\
Completed 2 weeks & 2 \\
Completed 3 weeks & 3 \\
Completed 4 weeks* & 6 \\
IY Parenting Programme (IYPP) & \\
Completed 1-6 weeks & 3 \\
Completed 7-14 weeks & 9 \\
Home visits (HVs) & \\
0 visits & 2 \\
1 visit & 3 \\
2 visits & 4 \\
3 visits & 3 \\
\hline
\end{tabular}

*Cycle 2 participants attended only 2 weeks of Positive Life Skills Program. As a result, completion of two weeks for Cycle 2 participants is considered $100 \%$ completion and these are added to the "Completed 4 weeks" group

varied according to level of need; 7 mothers received 2-3 visits whilst 3 received one visit $(M=1.6)$. Two mothers had declined the visits because one was in the process of separating from her partner, while the other was moving home over the course of the program.

\section{Quantitative Findings}

Data from the PFFs are summarized in Table 3. The closed question responses indicate that the support received from facilitators during both the PLSP and HVs was highly rated (above average) and the HVs, in particular, were rated as very useful both personally and in terms of enabling the parents to build their relationship with their child. The findings from the IY Parent Program Satisfaction Questionnaire show high levels of satisfaction with program components and delivery, specifically concerning the parent-child relationship, parenting techniques and confidence, teaching format and facilitator skills. The responses to the open-ended questions are included in the qualitative section below.

\section{Qualitative Findings}

Most participants took part in the program on a recommendation from the Family Support Worker $(n=6)$, while others were referred by social workers $(n=3)$, Key Worker $(n=1)$, ISPCC $(n=1)$ and statutory psychological services $(n=1)$. The qualitative analysis identified several aspects of the program which were considered beneficial to parents (Table 4). Four key themes were identified as important in relation to promoting engagement and positive program experiences, facilitator and group support and improved parenting 
Table 3 Parent satisfaction feedback data

\begin{tabular}{|c|c|c|}
\hline & Mean & SD \\
\hline \multicolumn{3}{|l|}{ Positive Life Skills Program $n=8^{* a}$} \\
\hline Describe the facilitators' support for you and your family? & 4.5 & 0.5 \\
\hline To what extent has the course helped you in your relationship with your children? & 3.8 & 1.1 \\
\hline To what extent do you think the course has helped you personally? & 3.8 & 0.6 \\
\hline \multicolumn{3}{|l|}{ IY Parent Satisfaction Questionnaire (selected responses) $n=12^{b}$} \\
\hline \multicolumn{3}{|l|}{ Overall program responses } \\
\hline The bonding/attachment that I feel with my child since I participated is (improved) & 6.7 & 0.5 \\
\hline $\begin{array}{l}\text { To what degree has the IY parenting program helped personal or family problems to (e.g. your marriage, your feel- } \\
\text { ings of support in general)? (helped very much) }\end{array}$ & 6.6 & 0.5 \\
\hline I feel that the approach used to enhance my child's social behavior in this program is (appropriate) & 6.1 & 1.1 \\
\hline How confident are you in parenting at this time? (confident) & 6.4 & 0.8 \\
\hline My overall feeling about achieving my goal in this program for my child and family is (positive) & 6.1 & 1.1 \\
\hline \multicolumn{3}{|l|}{ Teaching format-usefulness } \\
\hline Content of information presented & 6.4 & 0.8 \\
\hline Group discussion of parenting skills & 6.4 & 0.8 \\
\hline Use of practice/role play during group sessions & 6.5 & 0.8 \\
\hline Weekly handouts (e.g. refrigerator notes) & 5.9 & 1.3 \\
\hline Phone calls from the group leaders & 6.1 & 1.1 \\
\hline \multicolumn{3}{|l|}{ Specific parenting techniques-usefulness } \\
\hline Child-directed play & 6.4 & 1.1 \\
\hline Praise and encouragement & 6.3 & 1.5 \\
\hline Routines, responsibilities, rules & 6.1 & 1.1 \\
\hline Ignoring & 6.1 & 1.5 \\
\hline Time out to calm down and helping child control anger & 5.7 & 2.2 \\
\hline \multicolumn{3}{|l|}{ Evaluation of Group Leaders } \\
\hline I feel that the group leader's preparation/teaching was (excellent) & 6.8 & 0.8 \\
\hline Concerning the group leader's interest and concern in me and my problems with my child, I (like him/her) & 6.6 & 1.1 \\
\hline At this point, I feel that the group leader in the program was (helpful) & 6.4 & 1.1 \\
\hline \multicolumn{3}{|l|}{ Home visits $n=6^{* \# a}$} \\
\hline How would you describe the facilitators' support for you and your family? & 4.8 & 0.5 \\
\hline To what extent have the visits helped you in your relationship with your children? & 4.8 & 0.4 \\
\hline To what extent do you think the visits helped you personally? & 4.6 & 0.5 \\
\hline
\end{tabular}

*No data gathered for Cycle 3

\#Forms not completed by 2 participants in Cycle 2

${ }^{\text {a }}$ Responses for the PLSP and HVs were scored according to a Likert scale from 1-5 with 1 representing the least favorable response and 5 the most favorable response

${ }^{\mathrm{b}}$ Responses for the IYPP were scored according to a Likert scale from 1-7 with 1 representing the least favorable response and 7 the most favorable response

competencies and parental wellbeing. These are discussed in more detail in the following section along with a number of program challenges/barriers to engagement.

\section{Theme 1: Facilitator Skills, Home Visits and Group Support}

\section{Facilitator Skills}

All mothers commended the support received from the facilitators and specifically alluded to their approachability and rapport with the group. Facilitators were praised for their willingness to help at all times which was a source of reassurance and comfort for many mothers, enabling them to feel at ease with the group:

[the facilitators] were very good, down to earth, very open, willing to help ...(P10).

[the facilitators] were brilliant, always welcoming.. if you were having a problem during the week you could always contact them. (P3). 
Table 4 Main themes and sub-themes related to parent participants $(\mathrm{n}=12)$

Theme 1: Facilitator skills, home visits and group support

Facilitator skills

Home visits

Group support

Theme 2: Improved parent-child relationship and parenting practices Improved parent-child bond

Enhanced parent-child interaction and awareness of child development

Better discipline and routine

Theme 3: Improved parental wellbeing

Self-care and social support

Theme 4: Challenges and barriers to engagement

Program content more suitable for younger children

Dislike of vignettes/videos

Lack of knowledge of local parenting programs / poor advertising

Difficulty accessing program in rural area

It appears, in particular, that the personal qualities of the facilitators, namely their enthusiasm, openness and approachability, were critical in establishing trustworthy relationships with participants and further facilitated their active participation and engagement. Their ability to empathize with parents and understand the issues which influenced participation in the program, were essential in maintaining continued engagement. Facilitators were also reported to have assisted with transport or childcare needs:

I was having a problem on the first day I don't know where I was going to put [baby] and they told me that they are going to arrange for the lady from the family support to come ... and practical support such as childcare to and from the program. (P7).

\section{Home Visits}

The positive relationships between participants and facilitators were further enhanced through the home visits, during which the mothers were encouraged to voice any concerns about parenting and discuss any difficulties which they were experiencing in implementing the new parenting strategies/ techniques. Half of the mothers $(n=6)$ indicated that the visits were particularly useful if they felt apprehensive about confiding in the group, or when they needed extra time to practice the strategies learnt in the program. As one mother commented:

... because you have so many in the group and because of time constraints as well, it can be hard to try and hear everybody and people might not want things been spoke about in front of other people. But having the home visits ... you could say 'I was feeling a bit apprehensive and I didn't want to speak about this' ... (P3).

One participant described how the home visits had helped to reduce the feelings of isolation and loneliness she was experiencing at the time:

I found them helpful because you know sometimes you feel lonely and when you have visit you know that 'Oh my God, I'm not the only one in this world.' So I have somebody, somewhere that is thinking about me. (P7).

The quantitative feedback further supports the value of home visits. Participants rated the one-to-one support and empathetic approach of facilitators as the most helpful; for example, "being asked how I'm getting on", having the "opportunity to have a one to one without the group", taking "thoughts and feelings into consideration" suggested a level of meaningful engagement which had instilled a level of confidence in their parenting capabilities.

\section{Group Support}

Some mothers were initially apprehensive about sharing their difficulties with others, for fear of being perceived as a 'bad' or incapable parent. Indeed, a number of participants pointed to the benefits of the PLSP for providing a non-judgmental and non-stigmatizing space where they felt comfortable disclosing their parenting worries, and learning various techniques to manage stress and anxiety:

I thought the [PLSP] was good, listening to other people's experiences and all, I knew that it wasn't only me that was going through things with the teenagers and all, so it was good. (P4).

I was like I can't talk to anybody else because they will think I'm doing a bad job or but when you see other people that are going through similar struggles ... (P3).

These findings were supported with the open-ended responses from the PLSP questionnaire which also indicated that the program, above all else, had helped participants to open up regarding their difficulties "knowing that it was not just me who had stressful times with my kids" and alleviated the perceived sense of stigma associated with attending the program. Nine participants referred to the benefits of peer support in providing them with an invaluable opportunity to share frustrations, learn from each other, and, in turn, increase their confidence to participate more fully in the group process:

I found everybody was friendly everyone was there for the same reason, so there was none of this 'oh she's having problems with hers' everyone was going, 'well 
my young one does this and that' so we were all helping each other and everyone was friendly and welcoming. (P3).

And when you are going, you mix with people, you hear different stories, sometimes you will hear something that is worse than yours. Sometimes you will hear something that is better than yours. (P7).

\section{Theme 2: Improved Parenting Competencies}

\section{Improved Parent-Child Bond}

Most mothers $(n=9)$, having completed the program, remarked on an improved relationship with their children. Specific strategies were highlighted as particularly useful and included more positive interactions, greater one-on-one time with their child and increased use of praise, all of which enabled mothers to focus more on the positive aspects of their child's personality:

They were talking about regarding spending time with each child, even 20 min can make a difference. (P5).

Specifically, child-led play proved to be very popular, with many mothers reporting how it helped to build and strengthen the bond with their child:

I love the games because it is not just like the game, it is because of the kids, teaching us how to be with them, what to do and always a game, so I really loved them. (P9).

The bond is a lot closer again and that was actually my main goal when I started, to get the bond back. (P6).

\section{Enhanced Parent-Child Interaction and Awareness of Child Development Needs}

Six parents spoke of using more positive communication with their child and increasing their use of specific techniques such as 'active listening' skills and praise, all of which were seen to reinforce a more positive relationship with their child. One parent explained how "talking to my kids is different ... normally me and my kids roar at each other and instead now we talk to each other ... so that was good..." (P2). Mothers also described how improved communication had helped to minimize, and in some instances, prevent arguments and misbehavior:

If she doesn't want to be spoken to, she'll just cross her arms and we'll leave her alone and then she can come to us when she's ready rather than us chasing her around going 'what's wrong'..I can communicate with her a lot better ... so it's worked. (P3).
Praise worked well with mothers, particularly those who had younger children; "I realized even now if I praise him, he does something really good" (P9). Mothers were now far more likely to listen, and to communicate, in a more positive, and constructive, manner:

My biggest problem with [child] was the communication. So I think ... do not give too much instructions, give the warnings, okay in five minutes we are going, or in ten minutes, what would you like to do? (P8).

Some parents also appeared to have gained a better understanding of the emotional needs of their children. There was a greater awareness around their child's developmental needs and how a negative home environment can adversely influence, and often compound, difficulties in the home:

My neighbors were giving out that there was murder in this house every night or every day and so it has to stop. So when I started getting into the course [and] brought my leaflets to learn at home, bringing everything down to a low level where my kids could hear each other, we kind of understood each other, we helped each other out in the house ... (P2).

\section{Better Discipline and Routine}

Ignoring minor behavior, giving warnings, and learning not to over-react, were also identified as hugely beneficial in minimizing the occurrence of misbehavior. Seven parents described ignoring minor, less disruptive, behavior as preferable to using distraction techniques or issuing warnings. As one parent noted: "I don't shout as much anymore and they know now, I actually ignore them." (P1). Four mothers referred to the importance of establishing routines which often resulted in calmer and happier home environments:

[my daughter] wouldn't eat, so now she is eating more ... and so now we all sit in the kitchen at the table and she is eating all her food properly. (P6).

I put my foot down, [son] does his homework in school because he wasn't doing it at home and I say 'you only have one job when you come in and that's to empty your school bag and lunchbox' and whereas before I would let him run off. It's more structure. (P1).

The group also reported increased use of more positive disciplining strategies; for example, participants described the use of time-out, or the withdrawal of privileges or electronic devices (such as iPad or mobile phones) as helpful in minimizing the occurrence of misbehavior:

He used to be on the iPad all the time ... he was even playing it eating his dinner and all and then I said no, you're going to do this for an hour a day and that's it 
and then you can go out and play and get yourself all active ... and that came in handy it did and it actually worked. (P2).

The weekly homework was also valuable for encouraging and reinforcing the application of new strategies in the home. The ban on smacking children in Ireland-which has been in force since 2015-was instrumental in encouraging one non-Irish parent to use less harsh and negative strategies to manage her child's challenging behavior, and while initially skeptical, she was surprised at the effectiveness of the strategies:

As soon as I came to Ireland, I realized you can do something else other than slap the child. So when I saw it for myself, I couldn't believe that you can treat the child different than slap him. So I really liked it. (P9).

\section{Theme 3: Improved Parental Wellbeing}

\section{Importance of Stress Management Techniques, Self-Care and Social Support}

Numerous personal benefits from the program were also reported. Eight mothers described how the use of stress techniques, such as the 'pause button' and ignoring minor misbehavior, resulted in lower levels of stress feelings of greater control in difficult situations:

Before if he would do wrong, I would just fly off the handle, whereas now I can control myself more and maybe understand him more as well. (P6).

If something boiled up and they were fighting, I would be roaring at them all because I was stressed out but with that, it gave me the thing to step back and deal with it in a different way. So that helped. (P4).

Mothers also spoke of how the program enabled them to reflect on their own parenting style and in so doing, they became more aware of how their behavior affected their child. Those who had previously tended to over-react to their child's misbehavior, spoke of maintaining greater self-control:

The coping skills helped me the most because I realized it wasn't all [son's] behavior, it was how I was reacting to his behavior as well. (P6).

Knowing that I can control it, it was always a case of I've done something wrong ... Now it's a case of ok we all had our bad moments so it's not me or her, it's the two of us together so it's something that can be worked on. (P3).

As part of the program, self-care and making time for friends or family were actively encouraged. Consequently, many mothers reported an increase in social activities, such as taking time to spend with friends, all of which reduced stress and anxiety, and increased confidence:

When I was stressed, I wasn't going out. I wasn't talking to people. I didn't want to be around anybody ... Now I'm out every morning. I'm walking, going for coffee with friends, so it's made me come out of myself because I'm not stressed. (P3).

During the interviews, three parents referred to ongoing mental health difficulties which they felt had significantly reduced their ability to participate in the program. Two parents had also recently suffered bereavements which impacted on their attendance. However, the last two parents reported that their engagement with the program was maintained through the support of the group and in particular, through the empathy and help received from the facilitators. Another mother noted that she had sought help for her depression and encouraged other mothers, who were having similar problems, to seek assistance:

I found I was suffering from depression ... And then there were two other girls, and they had the same problem as well so I said, 'don't be afraid to go and get help if you need help, go and get help' .... (P11).

While participants' mental health issues posed a challenge to attendance, it was evident that both facilitator and peer support were instrumental in their continued participation. Post-program, three mothers reported missing the program and expressed an interest in either undertaking a booster session or attending other parenting programs in their locality. This suggests that the program bolstered selfesteem and enhanced parents' confidence:

I used to get up on a Wednesday morning and knew I had to be somewhere and then when the course was over and I was getting up and bringing the kids to school and coming home and I was like what am I going to do with myself? (P2).

\section{Theme 4: Challenges and Barriers to Engagement}

The mothers also reported a number of challenges with the program. For instance, five felt that it was not developmentally appropriate for older children, and while they reported learning from the program, they also suggested that program content should be adapted for teenagers:

... they could be maybe done [delivered] for an older age group, especially if you have a difficult child and there is going to be a dramatic change, maybe do it 'til even 12 [years]. (P1). 
One mother had difficulty understanding the content in the vignettes, while another four felt that the vignettes were outdated and too 'Americanized':

Sometimes the videos were too old ... like it is not relevant for this generation. (P10).

Everybody was sort of politically correct. There were no insights into how the parents were feeling. (P3).

Two mothers suggested the program should be more widely advertised, particularly in the preschool years when behavioral difficulties are more likely to emerge:

there are parents who wanted to attend but they didn't know about the program (P10).

Two participants remarked on the lack of parenting programs within their locality. Both were from different sites (rural and urban) and suggested that more advertising of the program would have been useful. A further two mothers felt that there had been little improvement in their children's behavior per se, pointing instead to improved coping mechanisms and reduced stress and anxiety when managing challenging behavior. One parent found some program topics were repetitive in nature

I found it boring for a while ... it was kind of the same things over and over, constantly repeating (P11)

whilst another felt she would have benefitted from more activity-based approaches such as more practice/role play.

Several contextual factors were highlighted which may have impacted on parental engagement. For instance, one mother highlighted the unsuitability of the program venue, indicating that it was a small room; she also felt that the attrition in her group had impacted on her enjoyment and engagement with the program. This parent participated in the program, which was delivered in the rural site and, as mentioned previously, access to the venue was more difficult in this area despite reimbursement of transportation costs; consequently, some participants declined to participate.

\section{Discussion}

This study explored parents' experiences and perspectives of a newly developed, community-based, multi-component parent training program designed to prevent CM. Firstly, we investigated participants' views and potential contextual factors which may have impacted attendance or program satisfaction. Overall, the findings point to the acceptability and perceived utility of the ChARM model amongst parent participants, in terms of both promoting parental capabilities and raising awareness of child needs and perspectives. Participants increasingly identified more with their children's emotional needs and recognized the effect of their behavior on their children. Consequently, many mothers reported controlling their anger and adopting more positive communication strategies to minimize difficult behavior. Greater use of more age-appropriate and non-coercive disciplining strategies was highlighted, including time-out and the withdrawal of privileges or electronic devices (e.g. mobile phones/iPads/tablets). Positive child behavior was encouraged through more frequent parent-interaction (specifically play time) as well as the use of praise and rewards and limit setting such as establishing new routines around dinner and bedtime. Children who experience $\mathrm{CM}$ are at increased risk for developing insecure attachment and without appropriate intervention, they are often more emotionally dysregulated and display more anger and aggression (Baer and Martinez 2006). Thus, strengthening parent-child interactions and the parent-child bond, are essential to the amelioration and prevention of child maltreatment (Cyr and Alink 2017). Furthermore, our findings are in line with the small number of similar studies of IYPP for children in the welfare system which found a greater occurrence of more nurturing and responsive parenting and reduction of harsh and critical parenting (Hurlburt et. al. 2013; Letarte et al. 2010). However, our findings offer a more personal perspective of the specific program areas considered to be most valuable, while highlighting the importance of positive facilitator relationships and peer support in introducing positive parenting strategies into the home and addressing parental wellbeing and isolation. Furthermore, the results indicate not only a high level of parental participation, but also the generalization of their skills to day-to-day family life over time.

Our findings also suggest that participants benefitted from the additional components. Families in CWS typically present with multiple needs that are not often addressed adequately by short-term, single component programs, and the provision of additional supports may be required to meet the complex needs of more vulnerable populations (Bolen, McWey and Schlee 2008). Families in CWS may not have the capacity or confidence to engage with formal supports or services; multiple stressors such as poverty, housing instability and social isolation and feelings of fear, shame and stigma lead to poor service uptake (Kemp et al. 2009). Our findings suggest further that parents can be positively engaged in preventative, evidence-based programs when they are fully supported and when individual and contextual factors are also taken into account.

As a 'pre-engagement' strategy, the newly developed PLSP may be a 'softer', less threatening support program offering parent participants a safe space to disclose their 
concerns, encourage interaction in a group setting, and receive basic support to develop their confidence and self-esteem. In so doing, it may also promote uptake and engagement with the IYPP through a greater focus on stress management techniques, and parenting confidence and resilience. The PLSP also addresses parents' practical and psychological barriers to engagement with services through the development of a positive facilitator-client relationship, enabling parents to feel supported and valued. Understanding parents' capacity to meet their child's needs and encouraging active collaboration in goal setting, were also central to ensuring ongoing engagement, especially with clients who may be seen as hostile or indifferent (Altman 2008). Retention among participants in the study was high and, taking into account the three non-completers, no parents were lost in the transition from the PLSP to the IYPP. Likewise, the collaborative format and strengths-based approach of the IYPP enhanced parental motivation by focusing on personal goals and strengths rather than deficits (Webster-Stratton and Reid 2010). Home visiting, in turn, reinforced the parenting techniques learnt in the IYPP and enabled participants to discuss and address individual parenting issues. Likewise, Barth and Liggett-Creel (2014) highlight the need for a more generic parent training program based on common components drawn from effective parenting programs. The ChARM program may have contributed to reported positive outcomes by utilizing the IYPP to improve child behavior and parenting skills, and incorporating additional program components such as the PLSP and home visits, may have enhanced practical and emotional support - all of which suggests that a broader, more flexible, approach is required to meet multiple parent needs.

An important aim of the ChARM model is to link parents with additional supports which can meet their often complex needs. Analysis of data from the impact evaluation revealed that intervention group families accessed more services (both community and statutory) post-program compared to the control group. Given that many families within CWS, often do not see the need and /or value of the service for their families (Altman 2008), this suggests that program participants were less fearful of services, and acknowledged the need to seek help and support for either themselves and/ or their children. However, the multiple demands faced by parents in CWS is contingent upon the availability of services in the community, which has important implications in terms of service planning and costs (Hackworth et al. 2018). Consistent with previous studies (e.g. Turney 2011), we also found attrition rates were higher for participants who reported being depressed (3 mothers dropped out of the program), therefore more attention needs to be paid to supports which address mental health issues, particularly depression, stress and anxiety.

\section{Importance of Engagement Strategies}

The multiple risk factors associated with $\mathrm{CM}$ pose a significant challenge to the use of evidence-based interventions, particularly in terms of the extent to which they can successfully engage and retain high-risk families (Axford et al. 2012; Ingoldsby 2010). All participants in this study were considered to have a high risk of CM ( 7 families were assigned to Level 3 and 4 representing chronic or serious problems), thereby requiring intensive supports. Despite this, the average IYPP attendance of around 8 sessions (10 sessions for retainers) compares favorably with that of other studies of IY programs conducted in CWS (Hurlburt et al. 2013; Marcynyszyn et al. 2011). So why was the program so successful in engaging high risk, vulnerable, families? Understanding the key barriers to implementation such as recruitment, retention and engagement, are critical to reducing attrition and optimizing positive outcomes (Moran, Ghate and van der Merwe 2004) and attempts to overcome these barriers may offer a valuable opportunity to explore what works for high risk groups in terms of parenting support interventions.

Firstly, a number of factors were seen to promote participant recruitment. Most referrals to the program were made by Family Support Workers (FSWs) who had previously established strong and trusting relationships with families. Research has shown that skilled home visitors are capable of identifying complex needs and encouraging families to access supports (Howard and Brooks-Gunn 2009), and such relationships may have influenced their decision to participate. Secondly, group support appeared to alleviate participants' concerns of feeling stigmatized by others judging their parenting skills, with some participants expressing their relief in realizing that other parents experienced similar difficulties with their child's behavior. Peer support also influenced engagement, as mothers spoke of enjoying the camaraderie within the group, with many reporting an increase in social activities and greater levels of self-esteem. Given that half of the mothers $(n=6)$ in this study were parenting alone, and five reported little practical support from family or friends, higher levels of support may reduce the risk of CM (Kim and MaguireJack 2015). Similar to research undertaken by Avellar and Supplee (2013) and Lees and Fergusson (2015), HVs contribute to a positive facilitator-parent relationship, reduced attrition, and lead to greater parenting satisfaction. Lastly, the dedication and commitment of program facilitators to supporting the needs of these vulnerable families and encouraging skill application, was noteworthy and appeared to be critical to minimizing program attrition. Specifically, parental reports suggest that facilitator qualities (empathy and sensitivity, knowledge of parenting 
situation) and relationships significantly facilitated program attendance. These have been previously identified in a number of studies conducted in both the US and UK, as key factors in promoting engagement and retention and, if absent, as significant barriers to families within CWS (Garcia et al. 2018; Whittaker and Cowley 2012).

\section{Study Strengths and Implications for Practice}

Poor participation and high drop-out rates remain a major challenge when working with high-risk families who may not participate, or be sufficiently motivated, to change (Love et al. 2013; Sanders and Kirby 2012). Parent perspectives of EBTs within the area of CWS are often overlooked (Kemp et al. 2009) and similar to studies undertaken by Drisko (2014) and Garcia et al. (2018), our findings point to the importance of strong parent-facilitator relationships, facilitator characteristics and peer support in encouraging engagement, and reducing the stigma which often surrounds parenting programs and improving parenting confidence. Quantitative data rarely capture such information (Kennett and Chislett 2012), thereby underlining the importance of giving parents a systematic voice in reporting their perceptions and experiences of supports within CWS, in order to get a clearer understanding of participant motivation and engagement (Lietz and Strength 2011).

This work has a number of important implications for clinical social work practice. Child welfare practitioners play a crucial role in engaging families with programs to address $\mathrm{CM}$, and they generally have a clear understanding of the contextual and psychological factors which limit engagement with treatment and support services. Furthermore, two of the four facilitators in the current study, were Social Workers who had been trained in the delivery of IYPP, and their knowledge and experience of the impact on parent-child attachment, of child adversity, neglect and/or abuse, as well as the influence of contextual issues, may have had additional benefits for children and families. This study is also one of only a few which have examined EBTs with a child welfare population, and potentially one of only a handful of innovative community-based programs with a strong focus on engagement. The ChARM program appears to represent a good 'fit' with families in CWS in this respect; attendance was above average, and the program was highly rated by participants. The findings reported here also suggest that delivery of additional components such as the PLSP and home visits together with an EBT (IYPP) promoted parental confidence and provided opportunities for one-to-one guidance on parenting difficulties. As outlined earlier, Barth and Liggett-Creel (2014) argue that in order to increase the uptake of EBTs within
CWS, parenting programs would substantially benefit from amalgamating essential parent training components as well as therapeutic strategies to optimize outcomes for families. Furthermore, according to Andrews and McMillan (2013), practitioners can reduce the risk of program failure by attending to contextual factors and promoting meaningful facilitator-client relationships. A key challenge for clinical social workers is the delivery of EBTs to populations with complex needs and using their skill and expertise to adapt the intervention to address the heterogeneity of populations that they serve (Wike et al. 2014).

\section{Limitations}

A small purposive sample was used which may limit the generalizability of the findings, although the sample did include a reasonable mix of married and single participants of varying ages, and was fairly evenly spread across all three cycles of delivery. The small sample size also prevented a comparison between urban and rural participants. Typically, rural participants would encounter more barriers to participation, not least the infrequency of such programs outside urban areas, as well as and transport and childcare issues (Koerting et al. 2013). It is possible that a larger number of rural participants in the study would have revealed more issues concerning access to local programs and supports. To encourage participation, a researcher who had previously gathered data in the impact evaluation, conducted most of the interviews, and some mothers may have responded to questions in a more positive light. In an effort to limit social desirability bias, researchers emphasized the confidentiality of the research and the importance of learning about participants' experiences (both positive and negative) of the program. No fathers participated in the research (and only one took part in the RCT), but the absence of fathers is reflective of their generally very low levels of participation in parenting programs more generally (Fletcher et al. 2011). Implementation difficulties also existed across both sites (rural and urban) and is typical of innovative programs where programs may need to be modified to meet the needs of participants (Durlak and DuPre 2008). To facilitate attendance, practitioners reduced the overall program duration in the rural site, and implementation difficulties were evident here (Cycle 3), both in terms of participant recruitment and collection of quantitative data. Feedback data were not available either from participants in this site (Cycle 3) and may have differed to that gathered in the urban sites (Cycles 1 and 2). Nevertheless, the quantitative findings revealed that facilitators adhered to the core principles and program content. 


\section{Conclusion}

The far reaching social, health and economic consequences of $\mathrm{CM}$ indicate an urgent need for more effective preventative services in order to address the complex needs of vulnerable families (Euser et al. 2015; Sethi et al. 2013). Thus, a key challenge for CWS providers, including social work practitioners, is to how best engage parents and maintain that engagement during program completion (Mytton et al. 2014), particularly as the limited reach of evidence-based parenting programs is frequently identified, but rarely studied (Baker et al. 2011). The provision of integrated services that are accessible, meaningful, and collaborative in nature, may minimize drop-out and optimize family outcomes (Hardy and Darlington 2008). Strategies should focus on building a positive relationship with families to sustain program participation (Axford et al. 2012), ensuring services are relevant and acceptable (Lewis et al. 2016) and augmenting services to better meet the needs of clients in the CWS (McWey et al. 2015). Moreover, the move from the 'child rescue' philosophy of CWS, to that of supporting parents, may yield greater benefits in terms of sustainable, long-term solutions to child welfare issues (Hardy and Darlington 2008). While existing literature supports the use of EBTs, and particularly parent training, in preventing CM (van der Put et al. 2018), engagement with such a highly vulnerable population is hugely problematic.

Implementation factors including time, costs and staff turnover are also significant barriers to the adoption of EBTs within CWS (Orlando, Barkan and Brennan 2019). In a recent meta-analysis of parenting training programs for CM, Gubbels, van der Put and Assink (2019) identified a number of factors required for interventions to be effective, including having a clear program structure and goal, high levels of program integrity and a strong professional-client relationship. An intensive program such as the ChARM model which combines an EBT, life skills and home visitation, may go some way towards meeting parents' unique needs, and providing adequate levels of support. Clinical social workers play a critical role in helping parents to engage with such interventions by establishing a trusting client-practitioner relationship and facilitating engagement with supports (both within the group and in the community) that can help to meet families' needs. However, much more large-scale research is required. As outlined earlier, this study was undertaken as part of a larger evaluation and our findings from the impact evaluation will assess the extent to which gains in knowledge translate into measurable change, while the process evaluation (e.g. data from staff involved in recruiting and delivering the program), should help to further elucidate the facilitative and inhibitive factors which influence implementation and program outcomes within existing social work service provision. Nonetheless, additional studies are urgently needed to inform the development and implementation of suitable evidence-based programs to prevent and minimize $\mathrm{CM}$.

\section{Appendix}

\section{Appendix Interview schedule}

1. How did you hear about the ChARM program?

2. What courses did you attend during the program?

3. Can you tell me about your experience of the courses you attended?

\section{Perceptions of program}

4. Which courses (prompt PLSP, IYPP, HVs) did you find useful?

- What aspects in these courses did you find helpful?

5. What courses did you find less useful?

- What aspects in these courses did you find less helpful?

6. What did you think about:

- The techniques taught?

- The group sessions?

- The home visits?

- Other courses/sessions you attended?

7. What would you change, if anything, about these aspects?

8. How did you get on with the other parents in the groups?

9. What did you think of the facilitators delivering the programs?

10. Are there any other services or any other supports which you have received recently?

\section{Benefits}

11. What benefits, if any, did you get from the courses?

- Child behavior and wellbeing. Please describe

- Relationship between parent and child(ren)

- Any improvements for yourself? 
(Probes: stress, health, personal issues, relationships with others).

- Any improvements for the family?

- Any other benefits that you feel as a result of attending the program?

\section{Challenges}

12. What challenges, if any, did you experience within the courses?

13. Did you experience any difficulties in getting to the courses?

- E.g. Transport/childcare, personal problems in attending.

14. To what extent were you supported by family or friends in attending these courses?

- How was it attending on a weekly basis?

- Were there any negative outcomes from participating in the program

\section{Conclusion}

15. Can you tell me how the courses might be improved in the future, if at all?

16. Overall, to what extent did this program meet your needs?

17. Is there anything you would like to add?

Additional questions for fathers:

-What made you decide to come to the parenting program?

- To what extent did the program cater for your needs as a father?

- To what extent did the program change your parenting practices?

\section{Interview schedule for families who dropped out of the program}

1. Can you tell me why you did not stay with the program?

2. What, if anything, did you dislike about the program?

3. To what extent were there childcare/access issues?

4. What, if anything, would you change about the program?

5. Can you tell me a little about how you and your family are getting on at the moment?

6. How about your child's behavior?

7. What services, if any, are you using to help you and your family?

8. Is there anything that you would like to add?

9. Would you try going to a similar program again?
Acknowledgements We are extremely grateful to all of the mothers and children who participated in the study. We also extend our thanks to our collaborators including Cherry Orchard Social Work Team, Archways, and Kildare Social Work Team, for assisting with participant recruitment and delivery of the program. Lastly, we acknowledge with thanks, the Health Research Board, Dublin, who funded this study under its 'Collaborative Applied Research Grants scheme in Population Health and Health Services Research' which was awarded to Professor Sinead McGilloway as the Principal Investigator (CARG/2012/17).

Author contributions YL analyzed the qualitative and quantitative data and wrote the paper. AS collected the data, assisted with the analysis and contributed to the writing of the paper. GH and SMcG contributed to the interpretation of the findings and to the writing and editing of the paper. SMcG is the Principal Investigator of the study and the larger ENRICH research program of which it is a part.

\section{Compliance with Ethical Standards}

Conflict of interest The authors declare that they have no conflict of interest.

Ethical Approval Ethical approval for this study was obtained from Maynooth University Social Research Ethics Sub-Committee and the National Child and Family Agency (Tusla) Research Ethics Committee.

Open Access This article is licensed under a Creative Commons Attribution 4.0 International License, which permits use, sharing, adaptation, distribution and reproduction in any medium or format, as long as you give appropriate credit to the original author(s) and the source, provide a link to the Creative Commons licence, and indicate if changes were made. The images or other third party material in this article are included in the article's Creative Commons licence, unless indicated otherwise in a credit line to the material. If material is not included in the article's Creative Commons licence and your intended use is not permitted by statutory regulation or exceeds the permitted use, you will need to obtain permission directly from the copyright holder. To view a copy of this licence, visit http://creativecommons.org/licenses/by/4.0/.

\section{References}

Altman, J. C. (2008). Engaging families in child welfare services: worker versus client perspectives. Child Welfare, 87(3).

Andrews, A. B., \& McMillan, L. (2013). Evidence-based principles for choosing programs to serve parents in the child welfare system. Administration in Social Work, 37(2), 106-119.

Asawa, L. E., Hansen, D. J., \& Flood, M. F. (2008). Early childhood intervention programs: Opportunities and challenges for preventing child maltreatment. Education and Treatment of Children, 31(1), 73-110

Avellar, S. A., \& Supplee, L. H. (2013). Effectiveness of home visiting in improving child health and reducing child maltreatment. Pediatrics, 132(Supplement 2), S90-S99.

Axford, N., Lehtonen, M., Kaoukji, D., Tobin, K., \& Berry, V. (2012). Engaging parents in parenting programs: lessons from research and practice. Child Youth Services Review, 34, 2061-2071.

Baer, J. C., \& Martinez, C. D. (2006). Child maltreatment and insecure attachment: A meta-analysis. Journal of reproductive and infant psychology, 24(3), 187-197. 
Baker, C. N., Arnold, D. H., \& Meagher, S. (2011). Enrolment and attendance in a parent training prevention program for conduct problems. Prevention Science, 12(2), 126-138.

Barth, R. P., \& Liggett-Creel, K. (2014). Common components of parenting programs for children birth to eight years of age involved with child welfare services. Children and Youth Services Review, 40, 6-12.

Bledsoe-Mansori, S. E., Bellamy, J. L., Wike, T., Grady, M., Dinata, E., Killian-Farrell, C., \& Rosenberg, K. (2013). Agency-university partnerships for evidence-based practice: A national survey of schools of social work. Social Work Research, 37(3), 179-193.

Bolen, M. G., McWey, L. M., \& Schlee, B. M. (2008). Are at-risk parents getting what they need? Perspectives of parents involved with child protective services. Clinical Social Work Journal, 36(4), 341-354.

Bowlby, J. (1982). Attachment (2nd ed.). New York: Basic Books.

Braun, V., \& Clarke, V. (2006). Using thematic analysis in psychology. Qualitative Research in Psychology, 3(2), 77-101.

Casillas, K. L., Fauchier, A., Derkash, B. T., \& Garrido, E. F. (2016). Implementation of evidence-based home visiting programs aimed at reducing child maltreatment: A meta-analytic review. Child Abuse \& Neglect, 53, 64-80.

Central Statistics Office. (2017). Survey on Income and Living Conditions (SILC). Cork: Central Statistics Office Publications.

Chen, M., \& Chan, K. L. (2016). Effects of parenting programs on child maltreatment prevention: A meta-analysis. Trauma, Violence, \& Abuse, 17(1), 88-104.

Currie, J., \& Spatz Widom, C. (2010). Long-term consequences of child abuse and neglect on adult economic well-being. Child Maltreatment, 15(2), 111-120.

Cyr, C., \& Alink, L. R. (2017). Child maltreatment: the central roles of parenting capacities and attachment. Current Opinion in Psychology, 15, 81-86.

Department of Children and Youth Affairs. (2017). Children First: National Guidelines for the Protection and Welfare of Children, 2017. Dublin: Government Publications.

Donelan-McCall, N., Eckenrode, J., \& Olds, D. L. (2009). Home visiting for the prevention of child maltreatment: Lessons learned during the past 20 years. Pediatric Clinics of North America, 56(2), 389-403.

Drisko, J. (2014). Research evidence and social work practice: The place of evidenced-based practice. Clinical Social Work Journal, 42, 123-133.

Durlak, J. A., \& DuPre, E. P. (2008). Implementation matters: A review of research on the influence of implementation on program outcomes and the factors affecting implementation. American Journal of Community Psychology, 41(3-4), 327.

Ethier, L. S., Lemelin, J. P., \& Lacharité, C. (2004). A longitudinal study of the effects of chronic maltreatment on children's behavioral and emotional problems. Child Abuse \& Neglect, 28(12), $1265-1278$.

Euser, S., Alink, L. R., Stoltenborgh, M., Bakermans-Kranenburg, M. J., \& van IJzendoorn, M. H. . (2015). A gloomy picture: a metaanalysis of randomized controlled trials reveals disappointing effectiveness of programs aiming at preventing child maltreatment. BMC Public Health, 15(1), 1068.

Fang, X., Brown, D. S., Florence, C. S., \& Mercy, J. A. (2012). The economic burden of child maltreatment in the United States and implications for prevention. Child Abuse \& Neglect, 36(2), $156-165$.

Fletcher, R., Freeman, E., \& Matthey, S. (2011). The Impact of Behavioural Parent Training on Fathers' Parenting: A meta-analysis of the Triple P Positive Parenting Program. Fathering A Journal of Theory, Research \& Practice about Men as Fathers, 9(3), 291-312.
Fortson, B. L., Klevens, J., Merrick, M. T., Gilbert, L. K., \& Alexander, S. P. (2016). Preventing child abuse and neglect: A technical package for policy, norm, and programmatic activities. Atlanta, GA: National Center for Injury Prevention and Control, Centers for Disease Control and Prevention.

Furlong, M., McGilloway, S., Bywater, T., Hutchings, J., Donnelly, M., Smith, S. M., \& O'Neill, C. (2010). Behavioural/cognitivebehavioural group-based parenting interventions for children age 3-12 with early onset conduct problems. The Cochrane Library, $1,1-14$.

Garcia, A. R., DeNard, C., Ohene, S., Morones, S. M., \& Connaughton, C. (2018). "I am more than my past": Parents' attitudes and perceptions of the Positive Parenting Program in Child Welfare. Children and Youth Services Review, 88, 286-297.

Gardner, F., \& Leijten, P. (2017). Incredible Years parenting interventions: Current effectiveness research and future directions. Current Opinion in Psychology, 15, 99-104.

Gilbert, R., Widom, C. S., Browne, K., Fergusson, D., Webb, E., \& Janson, S. (2009). Burden and consequences of child maltreatment in high-income countries. The Lancet, 373(9657), 68-81.

Gladstone, J., Dumbrill, G., Leslie, B., Koster, A., Young, M., \& Ismaila, A. (2014). Understanding worker-parent engagement in child protection casework. Children and Youth Services Review, 44, 56-64

Green, B. L., Ayoub, C., Bartlett, J. D., Von Ende, A., Furrer, C., Chazan-Cohen, R., et al. (2014). The effect of Early Head Start on child welfare system involvement: A first look at longitudinal child maltreatment outcomes. Children and Youth Services Review, 42, 127-135.

Gubbels, J., van der Put, C. E., \& Assink, M. (2019). The effectiveness of parent training programs for child maltreatment and their components: A meta-analysis. International Journal of Environmental Research and Public Health, 16(13), 2404.

Hackworth, N. J., Matthews, J., Westrupp, E. M., Nguyen, C., Phan, T., Scicluna, A., \& Nicholson, J. M. (2018). What influences parental engagement in early intervention? Parent, program and community predictors of enrolment, retention and involvement. Prevention Science, 19(7), 880-893.

Hardcastle, K; Bellis, M; Hughes, K; Sethi, D. (2015). Implementing child maltreatment prevention programmes: what the experts say. World Health Organization. Regional Office for Europe. https ://apps.who.int/iris/handle/10665/326346

Harden, B. J., Buhler, A., \& Parra, L. J. (2016). Maltreatment in infancy: A developmental perspective on prevention and intervention. Trauma, Violence, \& Abuse, 17(4), 366-386.

Hardiker, P., Exton, K., \& Barker, M. (1991). The social policy contexts of prevention in child care. British Journal of Social Work, 21, 341-359.

Hardy, F., \& Darlington, Y. (2008). What parents value from formal support services in the context of identified child abuse. Child \& Family Social Work, 13(3), 252-261.

Howard, K. S., \& Brooks-Gunn, J. (2009). The role of home-visiting programs in preventing child abuse and neglect. The Future of Children, 19(2), 119-146.

Hurlburt, M. S., Nguyen, K., Reid, J., Webster-Stratton, C., \& Zhang, J. (2013). Efficacy of the Incredible Years group parent program with families in Head Start who self-reported a history of child maltreatment. Child Abuse \& Neglect, 37(8), 531-543.

Ingoldsby, E. M. (2010). Review of interventions to improve family engagement and retention in parent and child mental health programs. Journal of Child and Family Studies, 19(5), 629-645.

Karatekin, C. (2014). A survey of organizations serving child welfare-involved families and children in Hennepin County, MN. Child and Adolescent Social Work Journal, 31(3), 197-235.

Kemp, S. P., Marcenko, M. O., Hoagwood, K., \& Vesneski, W. (2009). Engaging parents in child welfare services: Bridging 
family needs and child welfare mandates. Child Welfare, $88(1)$, $101-126$

Kemp, S. P., Marcenko, M. O., Lyons, S. J., \& Kruzich, J. M. (2014). Strength-based practice and parental engagement in child welfare services: An empirical examination. Children and Youth Services Review, 47, 27-35.

Kennett, D. J., \& Chislett, G. (2012). The benefits of an enhanced Nobody's Perfect Parenting Program for child welfare clients including non-custodial parents. Children and Youth Services Review, 34(10), 2081-2087.

Kim, B., \& Maguire-Jack, K. (2015). Community interaction and child maltreatment. Child Abuse \& Neglect, 41, 146-157.

Knerr, W., Gardner, F., \& Cluver, L. (2013). Improving positive parenting skills and reducing harsh and abusive parenting in low- and middle-income countries: A systematic review. Prevention Science, 14(4), 352-363. https://doi.org/10.1007/s11121-012-0314-1.

Koerting, J., Smith, E., Knowles, M. M., Latter, S., Elsey, H., McCann, D. C., et al. (2013). Barriers to, and facilitators of, parenting programmes for childhood behaviour problems: a qualitative synthesis of studies of parents' and professionals' perceptions. European Child \& Adolescent Psychiatry, 22(11), 653-670.

Lakhdir, M. P. A., Nathwani, A. A., Ali, N. A., Farooq, S., Azam, S. I., Khaliq, A., \& Kadir, M. M. (2019). Intergenerational transmission of child maltreatment: predictors of child emotional maltreatment among 11 to 17 years old children residing in communities of Karachi, Pakistan. Child Abuse \& Neglect, 91, 109-115.

Landers, A. L., McLuckie, A., Cann, R., Shapiro, V., Vistini, S., MacLaurin, B., et al. (2018). A scoping review of evidence-based interventions available to parents of maltreated children ages $0-5$ involved with child welfare services. Child Abuse \& Neglect, 76, 546-560.

LeCroy, C. W., \& Lopez, D. (2020). A randomized controlled trial of healthy families: 6-month and 1-year follow-up. Prevention Science, 21(1), 25-35.

Lees, D. G., \& Fergusson, D. M. (2015). A study to assess the acceptability of adding Home Parent Support along with the Incredible Years ${ }^{\circledR}$ parent programme. New Zealand Journal of Psychology (Online), 44(1), 40.

Letarte, M. J., Normandeau, S., \& Allard, J. (2010). Effectiveness of a parent training program "Incredible Years" in a child protection service. Child Abuse \& Neglect, 34(4), 253-261.

Levey, E. J., Gelaye, B., Bain, P., Rondon, M. B., Borba, C. P., Henderson, D. C., \& Williams, M. A. (2017). A systematic review of randomized controlled trials of interventions designed to decrease child abuse in high-risk families. Child Abuse \& Neglect, 65, 48-57.

Lewis, T., McElroy, E., Harlaar, N., \& Runyan, D. (2016). Does the impact of child sexual abuse differ from maltreated but non-sexually abused children? A prospective examination of the impact of child sexual abuse on internalizing and externalizing behavior problems. Child Abuse \& Neglect, 51, 31-40.

Lietz, C. A., \& Strength, M. (2011). Stories of successful reunification: A narrative study of family resilience in child welfare. Families in Society, 92(2), 203-210.

Love, S. M., Sanders, M. R., Metzler, C. W., Prinz, R. J., \& Kast, E. Z. (2013). Enhancing accessibility and engagement in evidencebased parenting programs to reduce maltreatment: Conversations with vulnerable parents. Journal of Public Child Welfare, 7(1), 20-38.

Maguire-Jack, K., \& Negash, T. (2016). Parenting stress and child maltreatment: The buffering effect of neighborhood social service availability and accessibility. Children and Youth Services Review, 60, 27-33.

Marcynyszyn, L. A., Maher, E. J., \& Corwin, T. W. (2011). Getting with the (evidence-based) program: An evaluation of the
Incredible Years Parenting Training Program in child welfare. Children and Youth Services Review, 33(5), 747-757.

McGilloway, S., Hickey, G., Leckey, Y., Leavy, S., O’Connor, S., \& Stokes, A. (2019). Evaluating the impact of universal early parenting support: ENRICHing families' lives. SUMMARY REPORT 1. Centre for Mental Health and Community Research (www.cmhcr.eu), Maynooth University, Maynooth, Ireland.

McGilloway, S., Mhaille, G. N., Bywater, T., Furlong, M., Leckey, Y., Kelly, P., \& Donnelly, M. (2012). A parenting intervention for childhood behavioral problems: a randomized controlled trial in disadvantaged community-based settings. Journal of Consulting and Clinical Psychology, 80(1), 116.

McWey, L. M., Holtrop, K., Wojciak, A. S., \& Claridge, A. M. (2015). Retention in a parenting intervention among parents involved with the child welfare system. Journal of Child and Family Studies, 24(4), 1073-1087.

Medical Research Council. (2000). A framework for the development and evaluation of RCTs for complex interventions to improve health. London: MRC.

Menting, A. T., de Castro, B. O., \& Matthys, W. (2013). Effectiveness of the Incredible Years parent training to modify disruptive and prosocial child behavior: A meta-analytic review. Clinical Psychology Review, 33(8), 901-913.

Mejdoubi, J., van den Heijkant, S. C., van Leerdam, F. J., Heymans, M. W., Crijnen, A., \& Hirasing, R. A. (2015). The effect of VoorZorg, the Dutch nurse-family partnership, on child maltreatment and development: A randomized controlled trial. PLoS One, 10(4), e0120182.

Moran, P., Ghate, D., Van Der Merwe, A., \& Policy research bureau. . (2004). What works in parenting support?: a review of the international evidence (pp. 49-99). London: Department for Education and Skills.

Mytton, J., Ingram, J., Manns, S., \& Thomas, J. (2014). Facilitators and barriers to engagement in parenting programs: a qualitative systematic review. Health Education \& Behavior, 41(2), 127-137.

Nanni, V., Uher, R., \& Danese, A. (2012). Childhood maltreatment predicts unfavorable course of illness and treatment outcome in depression: a meta-analysis. American Journal of Psychiatry, 169(2), 141-151.

Nikulina, V., Widom, C. S., \& Czaja, S. (2011). The role of childhood neglect and childhood poverty in predicting mental health, academic achievement and crime in adulthood. American Journal of Community Psychology, 48(3-4), 309-321.

Norman, R. E., Byambaa, M., De, R., Butchart, A., Scott, J., \& Vos, T. (2012). The long-term health consequences of child physical abuse, emotional abuse, and neglect: a systematic review and meta-analysis. PLoS medicine, 9(11), e1001349.

Orlando, L., Barkan, S., \& Brennan, K. (2019). Designing an evidencebased intervention for parents involved with child welfare. Children and Youth Services Review, 105, 104429.

Pidano, A. E., \& Allen, A. R. (2015). The Incredible Years series: A review of the independent research base. Journal of Child and Family Studies, 24(7), 1898-1916.

Price, J. M., Chamberlain, P., Landsverk, J., Reid, J. B., Leve, L. D., \& Laurent, H. (2008). Effects of a foster parent training intervention on placement changes of children in foster care. Child Maltreatment, 13(1), 64-75

Rostad, W. L., Moreland, A. D., Valle, L. A., \& Chaffin, M. J. (2018). Barriers to participation in parenting programs: the relationship between parenting stress, perceived barriers, and program completion. Journal of Child and Family Studies, 27(4), 1264-1274.

Sanders, M. R., \& Kirby, J. N. (2012). Consumer engagement and the development, evaluation, and dissemination of evidence-based parenting programs. Behavior Therapy, 43(2), 236-250. 
Schreiber, J. C., Fuller, T., \& Paceley, M. S. (2013). Engagement in child protective services: Parent perceptions of worker skills. Children and Youth Services Review, 35(4), 707-715.

Schreier, A., McCoy, K., Flood, M. F., Wilcox, B. L., \& Hansen, D. J. (2020). Early Head Start service use by families with courtsubstantiated maltreatment. Children and Youth Services Review, 108, 104602.

Self-Brown, S., Whitaker, D., Berliner, L., \& Kolko, D. (2012). Disseminating child maltreatment interventions: Research on implementing evidence-based programs. Child Maltreatment, 17(1), $5-10$.

Sethi, D., Bellis, M., Hughes, K., Gilbert, R., Mitis, F., \& Galea, G. (2013). European report on preventing child maltreatment. World Health Organization. Regional Office for Europe.

Sethi, D., Yon, Y., Parekh, N., Anderson, T., Huber, J., Rakovac, I., \& Meinck, F. (2018). European status report on preventing child maltreatment. Copenhagen: WHO Regional Office for Europe.

Sicotte, R., Letarte, M. J., Hélie, S., \& Mallette, I. A. L. (2018). Moderating role of the form of maltreatment experienced by children on the effectiveness of a parent training program. Child Maltreatment, 23(4), 334-343.

Smith, K. B., Humphreys, J. S., \& Wilson, M. G. (2008). Addressing the health disadvantage of rural populations: how does epidemiological evidence inform rural health policies and research? Australian Journal of Rural Health, 16(2), 56-66.

VERBI Software. MAXQDA 12 [computer software]. Berlin, Germany: Available from maxqda.com.

Staudt, M. (2007). Treatment engagement with caregivers of at-risk children: Gaps in research and conceptualization. Journal of Child and Family Studies, 16(2), 183-196.

Tong, A., Sainsbury, P., \& Craig, J. (2007). Consolidated criteria for reporting qualitative research (COREQ): a 32-item checklist for interviews and focus groups. International Journal for Quality in Health Care, 19(6), 349-357.
Turney, K. (2011). Maternal depression and childhood health inequalities. Journal of Health and Social Behavior, 52(3), 314-332.

van der Put, C. E., Assink, M., Gubbels, J., \& van Solinge, N. F. B. (2018). Identifying effective components of child maltreatment interventions: A meta-analysis. Clinical Child and Family Psychology Review, 21(2), 171-202.

Webster-Stratton, C., \& Hancock, L. (1998). Parent training: content, methods and processes. In E. Shafer (Ed.), Handbook of Parent Training. 2nd ed. New York: Wiley and Sons.

Webster-Stratton, C., \& Reid, M. (2010). Adapting the Incredible Years, an evidence-based parenting programme, for families involved in the child welfare system. Journal of Children's Services, 5(1), 25-42.

Whittaker, K. A., \& Cowley, S. (2012). An effective programme is not enough: A review of factors associated with poor attendance and engagement with parenting support programmes. Children and Society, 26(2), 138-149.

Wike, T. L., Bledsoe, S. E., Manuel, J. I., Despard, M., Johnson, L. V., Bellamy, J. L., \& Killian-Farrell, C. (2014). Evidence-based practice in social work: Challenges and opportunities for clinicians and organizations. Clinical Social Work Journal, 42(2), 161-170.

Publisher's Note Springer Nature remains neutral with regard to jurisdictional claims in published maps and institutional affiliations.

Yvonne Leckey Yvonne Leckey is a Senior Researcher in the Department of Psychology with research expertise in early intervention and prevention initiatives, and specifically child health and development. Particular interests include health of at risk populations and understanding how services engage more vulnerable families and identifying barriers to participation. 